\title{
Sodium bicarbonate ingestion does not restore the decrement in high-intensity exercise capacity induced by a $27 \mathrm{~h}$ Fast
}

\author{
C. P. Lambert ${ }^{1}$, D. Ball ${ }^{2}$, and R. J. Maughan ${ }^{3}$
}

\author{
${ }^{1}$ University of Toledo, Toledo, USA \\ ${ }^{2}$ School of Sport, Exercise and Health Sciences, Loughborough University LE11 3TU, \\ United Kingdom \\ ${ }^{3}$ School of Life Sciences, Heriot Watt University, Edinburgh, EH14 4AS, United King- \\ dom
}

\begin{abstract}
Summary. A $24 \mathrm{~h}$ fast reduces the time to exhaustion at $100 \%$ of $\dot{V}_{2}$ max relative to the $4 \mathrm{~h}$ postabsorptive condition. A consequence of fasting is a metabolic acidosis, which may be a cause of the premature fatigue. The purpose of this investigation was to orally administer sodium bicarbonate in combination with a one day (27 h) fast and determine whether exercise capacity was restored to that of the fed condition ( $3 \mathrm{~h}$ post-absorptive). Six healthy men (mean $\pm S D$ : age $26 \pm 3$ years; mass $68,3 \pm 6,0 \mathrm{~kg}$; height 1,75 $\pm 0,04 \mathrm{~m}$; and $\mathrm{VO}_{2} \max 55,4 \pm 7 \mathrm{ml} / \mathrm{kg} / \mathrm{min}$ ) participated after giving their written consent. Subjects exercised to exhaustion at $98 \pm 2 \%$ of $\dot{V}$ max on 4 occasions separated by seven days. Prior to two trials ( $F T$ and FC) subjects fasted for $27 \mathrm{~h}$ while prior to the other two trials subjects maintained their normal diet and were $3 \mathrm{~h}$ post-absorptive (NDT and NDC). On one of the fasted trials (FT) and one of the normal diet trials (NDT) subjects ingested 3,6 mmol $\mathrm{NaHCO}_{3}$ per kilogram of body mass beginning three hours prior to exercise. On the remaining fasted (FC) and normal diet (NDC) trials subjects ingested a placebo, 3, $0 \mathrm{mmol} \mathrm{CaCO}_{3} / \mathrm{kg}$ body mass, beginning three hours prior to exercise. Exercise duration after both FC and FT was significantly lower than that attained after both NDC and NDT $(200 \pm 14,162 \pm 14,200 \pm 15$, and $169 \pm 19 \mathrm{~s}$ for NDC, FT, NDT, and FC; $p<0,001)$. In conclusion, sodium bicarbonate ingestion after a $27 \mathrm{~h}$ fast did not restore high-intensity exercise capacity to that attained in the $3 \mathrm{~h}$ post-absorptive condition, suggesting that a fasting-induced acidosis is not a significant component in the reduced performance in the fasted state.
\end{abstract}

Key words: sodium bicarbonate, high-intensity exercise, fasted trials, normal diet.

\begin{abstract}
Резюме. Протягом 24 годин швидко скорочується час виснаження, практично на 100 \% відновлюється показник $\mathrm{VO}_{2}$ тах по відношенню до 4 годин постпоглинаючого стану. Наслідком такого стану може бути метаболічний ацидоз, який є причиною передчасної втоми. Мета цього дослідження - регуляція рівня бікарбонату натрію завдяки пероральному прийому протягом одного дня (24 години) з метою прискорення та визначення толерантності відновлення організму після фізичного навантаження у поствідновлювальному періоді (3 години після завершення). У дослідженнях брали участь шість здорових чоловіків за особистою письмовою згодою.

Уході дослідження проводилось вивчення підвищення відновлення організму після тривалого фізичного навантаження на фоні прийому спеціальних бикарбонат натрію складових фармакологічних препаратів по відношенню до результатів осіб, які приймали препарати типу «плацебо» і знаходились у звичайному для них (щоденному) режимі харчування.

Ключові слова: бікарбонат натрію, фізичні навантаження високої інтенсивності, обмежені випробування, звичайний режим харчування.
\end{abstract}

\section{Introduction}

Short term $(\sim 24 \mathrm{~h})$ fasting results in a large increase in circulating concentrations of free fatty acids and ketone bodies (Loy et al. 1986, Nieman et al. 1987, Gleeson et al. 1988) as well as a significant reduction in hepatic glycogen stores (Nilsson and Hultman, 1973). The effect of such a fast on skeletal muscle glycogen stores, however, is less clear with some authors reporting a decline in muscle glycogen following fasting and others reporting no effect. For example, Hultman (1967) reported that a $24 \mathrm{~h}$ fast reduced muscle glycogen levels by $25 \%$ and this is supported by Coyle, Coggan et al. (1985) who reported that 
muscle glycogen levels were $42 \%$ lower immediately prior to exercise in subjects who fasted for 16 hours when compared to the glycogen levels attained when subjects fasted for $12 \mathrm{~h}$ and ingested a $145 \mathrm{~g}$ carbohydrate feeding $4 \mathrm{~h}$ prior to the muscle biopsy. In contrast, Maughan and Williams (1978) and Loy et al. (1986) reported that a $24 \mathrm{~h}$ fast had no significant effect on muscle glycogen levels. Nonetheless, in humans, short term fasting has been shown to have a detrimental effect on the performance of prolonged exercise of moderate intensity (Pequignot et al. 1980, Loy et al. 1986, Nieman et al. 1987, Maughan and Gleeson 1988).

The effects of short term fasting on high-intensity exercise capacity are not well documented. At fatigue during high-intensity exercise muscle glycogen (in samples of mixed fibre type) remains considerably higher than the level believed to limit the contribution of glycogenolysis to energy provision (Hermansen 1981). In addition, Katz et al. (1986) calculated that blood borne glucose provides only $1 \%$ of the carbohydrate utilized during exercise to fatigue at $100 \%$ of $\dot{\mathrm{V} O 2}$ max. Based on these findings, the reduction in hepatic glycogen stores and possible reduction in muscle glycogen stores associated with a $24 \mathrm{~h}$ fast should have little effect on muscle energy provision during high-intensity exercise. However, Gleeson et al. (1988) reported that, when compared to the $4 \mathrm{~h}$ post absorptive condition, a $24 \mathrm{~h}$ fast reduced exercise duration at a power-output corresponding to $100 \%$ of maximum oxygen uptake ( $\dot{\mathrm{V}}_{2}$ max) by $13 \%$. An additional consequence of the $24 \mathrm{~h}$ fast in the investigation of Gleeson et al. (1988) was lower plasma $\mathrm{HCO}_{3}^{-}$and blood base excess (BE) prior to exercise relative to the values obtained in the $4 \mathrm{~h}$ post-absorptive condition. Because alterations in extracellular acid-base status influence the rate of lactate $/ \mathrm{H}+$ efflux from muscle (Hirche et al. 1975), and under some circumstances influence high-intensity exercise capacity (Jones et al. 1977, Sutton et al. 1981, Costill et al. 1984), it is possible that the alterations in acid-base status associated with fasting was a cause of fatigue in the investigation of Gleeson et al. (1988).

The purpose of this investigation was to determine whether the ingestion of sodium bicarbonate, designed to reverse a fasting-induced acidosis, after fasting for 24 hours would restore high-intensity exercise capacity to that observed in the fed condition.

Subjects. Six healthy men (mean+SD: age $26 \pm 3$ years; mass $68,3 \pm 6,0 \mathrm{~kg}$; height
$1,75 \pm 0,04 \mathrm{~m} ; \dot{\mathrm{VO}}_{2} \max 55,4 \pm 7 \mathrm{ml} / \mathrm{kg} / \mathrm{min}$ ) participated in this investigation after being informed of the risks involved and giving their written consent. All subjects participated in some form of regular physical activity. This investigation was approved by the local ethics committee before its initiation.

Preliminary Testing. Each subjects $\dot{\mathrm{V}}_{2} \max$ was determined using a discontinuous protocol on an electrically braked cycle ergometer. $\grave{\mathrm{V}}_{2} \max$ was verified approximately two days after the initial assessment. Seven days prior to the initial experimental trial each subject participated in a familiarization trial which was identical to the experimental trials except that there was no treatment administration and fewer blood samples were obtained.

Experimental Testing. On four separate occasions separated by seven days each subject exercised to exhaustion on an electrically braked cycle ergometer at a power output equivalent to

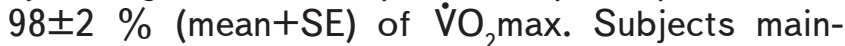
tained a pedal cadence of $75-80$ revolutions $/ \mathrm{mi}-$ nute. Exhaustion was considered the point at which the subject could no longer maintain a pedal cadence of 50 revolutions/minute.

Prior to two of the trials (FT and FC) subjects fasted for $27 \mathrm{~h}$ while prior to the remaining two trials subjects maintained their normal diet and were $3 \mathrm{~h}$ post-absorptive (NDT and NDC). On one of the fasted trials (FT) and one of the normal diet trials (NDT) subjects were on the Test condition and ingested $3,6 \mathrm{mmol} \mathrm{NaHCO}_{3}$ per kilogram of body mass $(0,3 \mathrm{~g} / \mathrm{kg}$ body mass) over two hours beginning three hours prior to exercise. On the remaining fasted (FC) and normal diet (NDC) trials subjects were on the Control condition and ingested $3,0 \mathrm{mmol} \mathrm{CaCO}_{3} / \mathrm{kg}$ body mass $(0,3 \mathrm{~g} / \mathrm{kg}$ body mass) as placebo over two hours beginning three hours prior to exercise. Treatment order was randomized and $\mathrm{NaHCO}_{3}$ and $\mathrm{CaCO}_{3}$ administration was double blind: $\mathrm{NaHCO}_{3}$ and $\mathrm{CaCO}_{3}$ were administered in gelatin capsules. The final meal before both the fasted and normal diet conditions was 3,15 MJ of a complete nutritional liquid (Ensure Plus, Abbott Laboratories Ltd, Queensborough, Kent ME11 5E) consisting of $53 \%$ carbohydrate, $16,7 \%$ protein, and $30 \%$ fat. In each case the final meal was administered after a $10 \mathrm{~h}$ overnight fast, and subjects were instructed to consume the same final meal at the same time on the preceding evening. All trials were performed between 11:00 and 13:00 hours and each subject performed his four trials at the same time of day. Subjects maintained their normal pattern of physical activity and 
diet between trials and abstained from strenuous exercise and alcohol consumption for 48 hours preceding each trial.

Before the experimental trials each subject reported to the laboratory and his nude body weight was obtained. The subject's hand was then immersed in water of $42^{\circ} \mathrm{C}$ for $10 \mathrm{~min}$ to arterialize the venous blood. This method has previously been validated by Forster et al. (Forster, Dempsey et al. 1972). A $21 \mathrm{~g}$ butterfly cannula was then inserted into a vein on the dorsal surface of the subject's hand. This allowed for sampling of arterializedvenous blood immediately before ingestion of the final meal on the fasted $(-27 \mathrm{~h})$ condition, before ingestion of the $\mathrm{NaHCO}_{3}$ and $\mathrm{CaCO}_{3}$ on the fasted condition $(-3 \mathrm{~h})$, before ingestion of the final meal and $\mathrm{NaHCO}_{3}$ and $\mathrm{CaCO}_{3}$ on the Normal Diet condition $(-3 \mathrm{~h})$, immediately prior to exercise (0), and at $2,4,6,10$, and $15 \mathrm{~min}$ after exercise. The cannula was kept patent between samples by flushing with a small volume of isotonic saline.

Analytical Methods. At each sampling point $2,5 \mathrm{ml}$ of blood for determination of selected metabolites was obtained and dispensed into a tube containing $\mathrm{K}_{3}$ EDTA. In duplicate, $100 \mathrm{ul}$ of this blood was deproteinized in $1 \mathrm{ml}$ of $0,3 \mathrm{~N}$ perchloric acid, mixed, placed in iced water, and subsequently centrifuged : blood glucose concentration was determined on this sample using the glucose oxidase method (Boehringer Coroporation, Lewes, UK) while blood lactate, alanine, beta-hydroxybutyrate (B-HB) concentrations were determined using the methods of Maughan (1982). An additional aliquot $(1 \mathrm{ml})$ of this blood was placed in an empty tube, centrifuged and the plasma drawn off for the determination of glycerol concentration (Boobis and Maughan 1983).

Statistical Analysis. Endurance capacity data was analyzed by one-way ANOVA for repeated measures. All other data were analyzed by threeway ANOVA (Bicarbonate or placebo $X$ fasted or fed $X$ time) with repeated measures on the time factor. Following a significant main effect or interaction, the Newman-Keuls post-hoc analysis was used to determine the location of differences between pairs of means. Differences for all analyses were considered significant if they achieved the probability level of 0.05 . Descriptive data of the subjects are presented as mean \pm SD. All other data in text, tables, and figures are presented as mean \pm SEM. Standard error bars on the figures have been removed for clarity.

\section{Results}

Exercise Capacity. Exercise duration after both FC and FT was significantly lower than that attained after both NDC and NDT $(200 \pm 14$, $162 \pm 14,200 \pm 15$, and $169 \pm 19 \mathrm{~s}$ for NDC, FT, NDT, and FC; $p<0,001)$. The magnitude of the reduction as a result of fasting was $16 \pm 5 \%$ when subjects were on the Control condition (FC vs. NDC) and $19 \pm 3 \%$ when subjects were on the Test condition (FT vs. NDT).

Body Mass. The $27 \mathrm{~h}$ fast resulted in a greater body weight reduction than the normal $\operatorname{diet}(0,27 \pm 0,10,-0,47 \pm 0,24,0,42 \pm 0,50$, $-0,90 \pm 0,33 \mathrm{~kg}$ for NDC, FT, NDT, FC; $p<0,003$; $p=0,121$ for FT vs. NDC; $p=0,051$ for FT vs. NDT; $p=0,01$ for FC vs. NDC; and $p=0,004$ for FC vs. NDT.

Effects of Fasting on Selected Metabolites. Fasting resulted in a significant change in the profile of the blood metabolites. There was a $13 \%$ reduction $(p=0,0008)$ and a $14,0 \%$ reduction $(p=0,0012)$ in the glucose concentration from $-27 \mathrm{~h}$ to $-3 \mathrm{~h}$ and from $-27 \mathrm{~h}$ to 0 , respectively. The alanine concentration was significantly lower by $17,8 \%(p=0,0100)$ and by $14,8 \%(p=0,0341)$ from $-27 \mathrm{~h}$ to $-3 \mathrm{~h}$ and from $-27 \mathrm{~h}$ to time 0 , respectively. The lactate concentration was reduced by $31 \%(p=0,0276)$ from $-27 \mathrm{~h}$ to $-3 \mathrm{~h}$ but was not reduced from $-27 \mathrm{~h}$ at $0 \mathrm{~h}$. Beta hydroxybutyrate was elevated by $22,6 \%$ (NS) and by $85 \%$ $(p=0,0008)$ at $-3 \mathrm{~h}$ and $0 \mathrm{~h}$ relative to $-27 \mathrm{~h}$. Finally, glycerol was elevated by $25 \%$ at $-3 \mathrm{~h}(\mathrm{p}=0,0378)$ and by $64,8 \%$ at 0 hours $(p=0,0002)$ relative to $-27 \mathrm{~h}$

Pre and Post-Exercise Metabolites. A main effect of the exercise, in combination with the dietary history, was observed with glucose being significantly lower in the fasted condition than the fed condition $(p=0,01)$. There was a significant interaction for nutritional condition (fasted or fed) vs. time $(p=0,0016)$ for the glucose concentration. However, subsequent Newman-Keuls posthoc analysis found no pairwise differences at any time point between fasted and fed conditions.

The post-exercise alanine concentration was significantly higher at all time points $(p<0,0001)$ compared with the pre-exercise time point, irrespective of fasting or $3 \mathrm{~h}$ post-prandial condition.

There was a significant nutritional condition (fasted or fed) X time effect for the lactate concentration; however, no significant differences between pairs of means were observed. There was a trend for a main effect $(p=0,0672)$ of a lower concentration of lactate observed in the fasted condition compared with the fed condition.

There was a significant Nutritional Condition (fasted or fed) X Time effect for beta hydroxybutyrate; however, the Newman -Keuls 


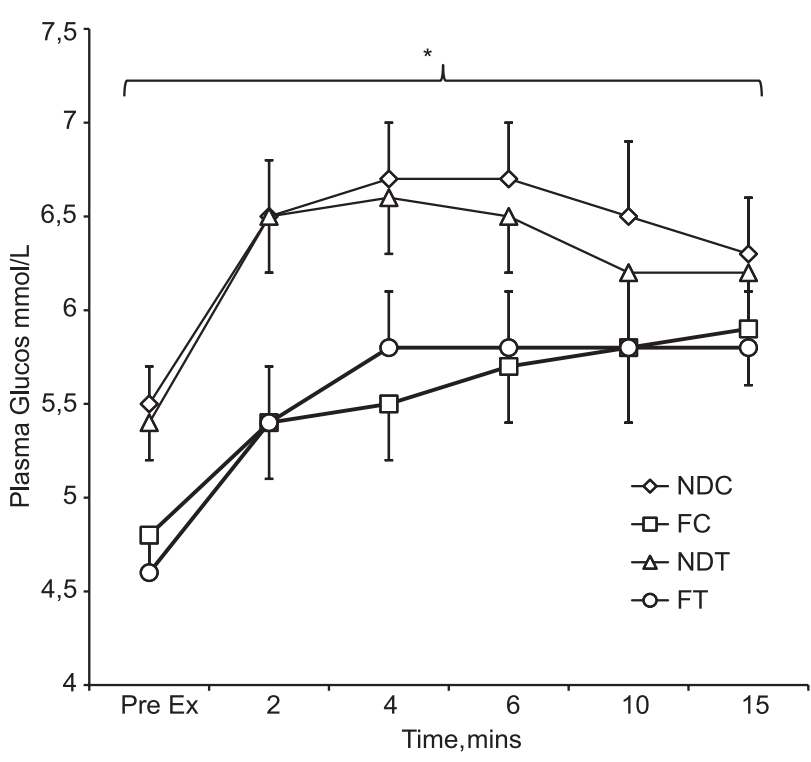

Figure 1. Glucose concentration $(\mathrm{mmol} / \mathrm{L})$ pre exercise (Pre Ex) and 2, 4, 6, 10, and 15 minutes after exhaustion. Data are presented as mean \pm SEM. Asterisk denotes a significant main effect between fasted and normal diet conditions $(p<0,01)$

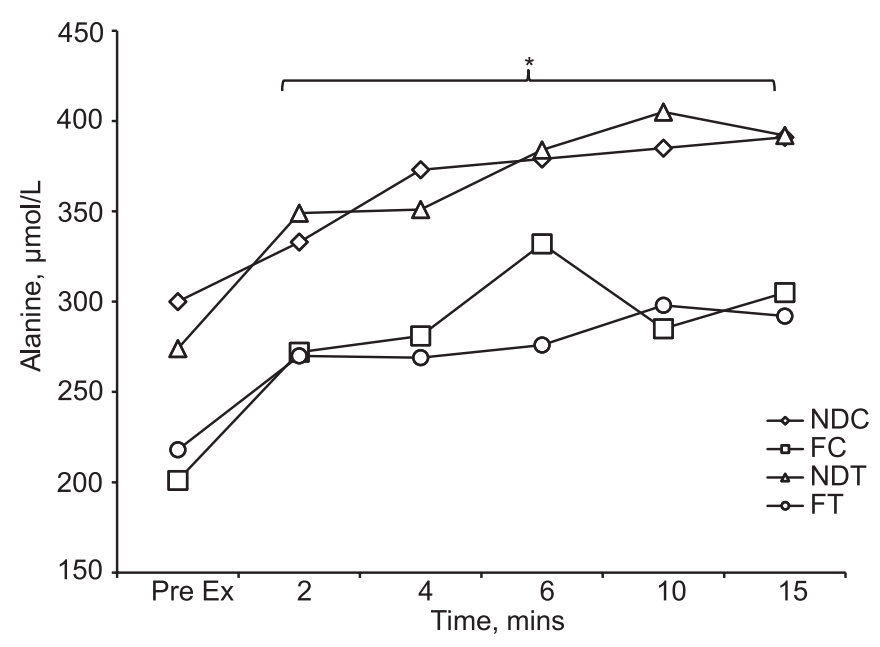

Figure 2. Alanine concentration $(\mu \mathrm{mol} / \mathrm{L})$ pre exercise (Pre Ex) and 2, 4, 6, 10, and 15 minutes after exhaustion. Error bars have been omitted for clarity. Asterisk denotes a significant time effect vs. pre-exercise $(p<0,0001)$

analysis revealed no pairwise significant differences. However, the pre-exercise beta hydroxybutyrate was $118 \%$ higher for the fasted conditions than the fed conditions $(p=0,191)$.

There was a significant Nutritional Condition (fasted or fed) X Time effect for glycerol but the Newman-Keuls analysis did not reveal any pairwise significant differences. There was a significant fasting main effect with the values for the fasted

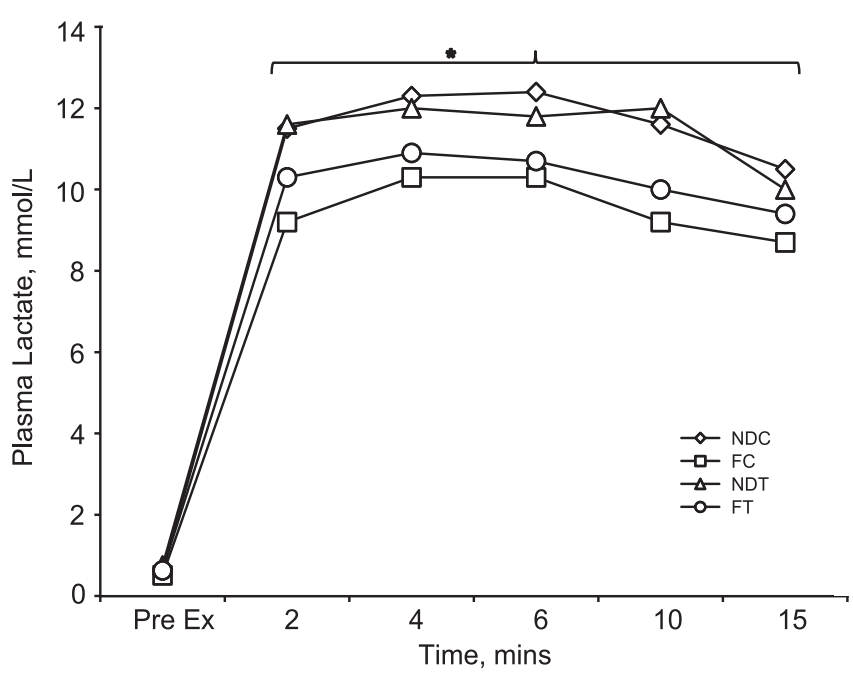

Figure 3. Lactate concentration $(\mathrm{mmol} / \mathrm{L})$ pre exercise (Pre Ex) and 2, 4, 6, 10, and 15 minutes after exhaustion. Error bars have been omitted for clarity. Asterisk denotes a significant time effect vs pre-exercise $(p<0,05)$

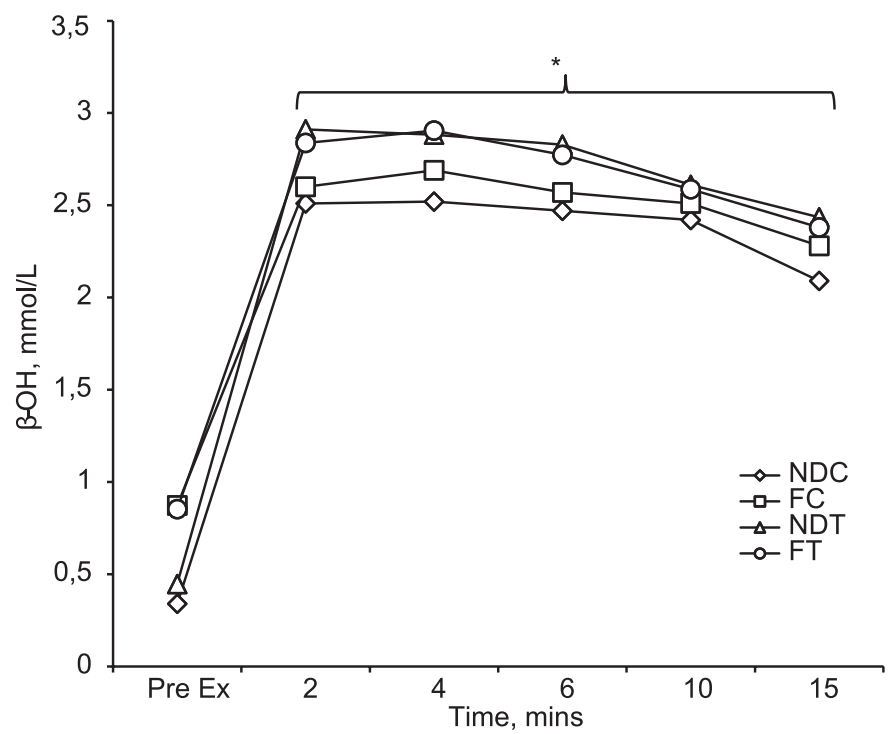

Figure 4. Beta-hydroxybutyrate concentration ( $\mathrm{mmol} / \mathrm{L}$ ) pre exercise (Pre Ex) and 2, 4, 6, 10, and 15 minutes after exhaustion. Error bars have been omitted for clarity.

Asterisk denotes a significant time effect $(p<0,05)$

condition being significantly higher than for the fed condition $(p=0,0013)$.

\section{Discussion}

The major finding of the present investigation was that the ingestion of sodium bicarbonate did not reverse the negative effects of fasting on high-intensity exercise capacity. Further, sodium bicarbonate ingestion did not improve time to fatigue at $100 \%$ 


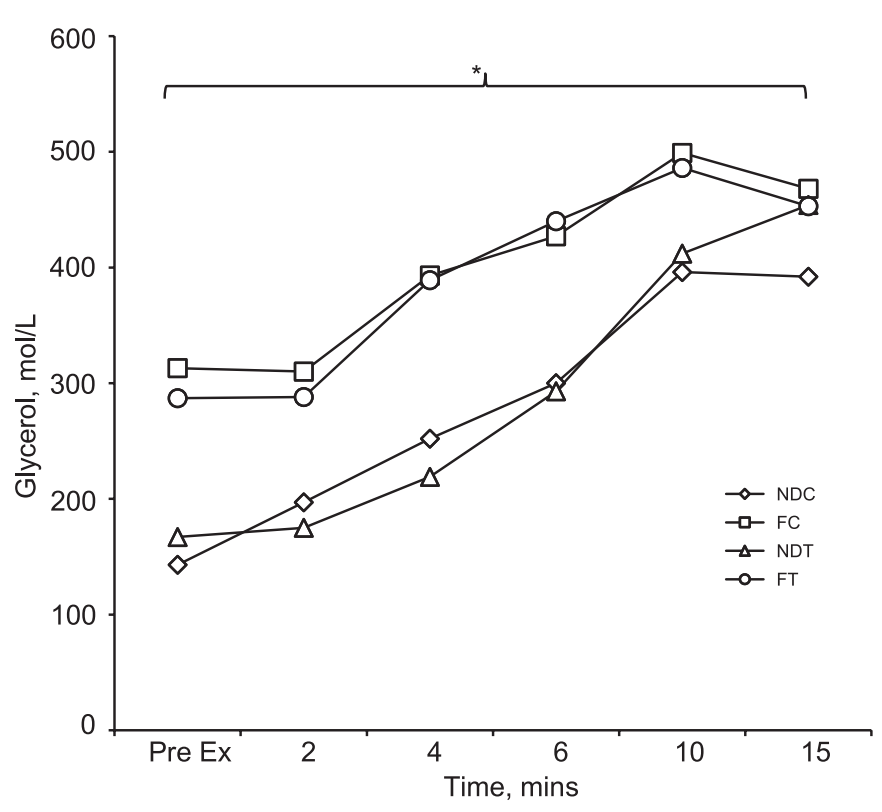

Figure 5. Glycerol concentration ( $\mu \mathrm{mol} / \mathrm{L}$ ) pre exercise (Pre Ex) and 2, 4, 6, 10, and 15 minutes after exhaustion. Error bars have been omitted for clarity. Asterisk reveals a significant fasting vs. normal diet main effect ( $p<0,001)$

of $\dot{\mathrm{V}}_{2}$ max in the fed condition. Thus, it is likely that factors other than circulatory acidosis are responsible for fatigue during high-intensity exercise in the fasted condition. Additionally, because sodium bicarbonate ingestion did not improve exercise capacity in the fed condition, circulatory acidosis does not appear to be the cause of fatigue during exercise at $\sim 100 \%$ of $\dot{\mathrm{V}}_{2} \max$ in the fed condition.

It is possible that fasting reduces the $\mathrm{pH}$ of the intramuscular compartment. Larson et al. (1991) reported that the increase in the hydrogen ion concentration in muscle with intense exercise was significantly correlated $(r=0,84)$ with the duration of the fast prior to exercise. Therefore, it appears plausible that the premature fatigue induced by fasting was due to intramuscular acidosis that persisted despite sodium bicarbonate ingestion. Muscle $\mathrm{pH}$ and buffering capacity data were not obtained in the present investigation. However, if the alterations in acid-base status induced by the $27 \mathrm{~h}$ fast negatively impaired intramuscular acidbase status, it is possible that the $3 \mathrm{~h}$ period prior to exercise was not of sufficient duration and/or the induced alkalosis on treatment FT was not of sufficient magnitude to reverse these alterations. Thus, it is possible that intramuscular $\mathrm{pH}$ and/or buffering capacity were reduced prior to exercise on both of the fasting trials relative to the trials carried out in the post-absorptive condition and that this was a cause of the reduced exercise capacity.
Muscle glycogen data were not obtained in the present investigation. However, it is possible that muscle glycogen levels were lower in the fasted conditions when compared to the normal diet condition (Hultman 1967; Coyle et al. 1985). A difference in muscle glycogen between conditions would be important during prolonged exercise as the depletion of muscle glycogen stores is highly related to the onset of fatigue (Bergstrom et al. 1967). However, because muscle glycogen levels (measured in mixed fibre samples) remain high at the point of fatigue, the availability of muscle glycogen is not believed to be important to the performance of high-intensity exercise (Hermansen 1981). The data obtained from mixed fiber biopsy samples may be misleading; however, as the glycogenolytic (Harris et al. 1976) and glycolytic (Essen et al. 1975) capacities as well as the ability to generate power (Faulkner et al. 1986) are markedly higher in type II than in type I fibers. Greenhaff et al. (1991) have reported that during intense electrical stimulation to fatigue the glycogenolytic rate in type II fibers was 20 times higher than in type I fibres. In addition, these investigators suggested that because of the high glycogenolytic rate of type II fibres, reduced glycogen availability may limit the rate of ATP turnover in these fibres and therefore result in fatigue during high-intensity contraction. Thus, if muscle glycogen levels were lower in the fasted when compared with the normal diet condition prior to exercise, it is possible that reduced muscle glycogen availability in type II fibres was the cause of the lowered endurance capacity in FT and FC as compared to NDT and NDC. Supporting the contention that reduced carbohydrate availability can limit the performance of high-intensity exercise are investigations which suggest that a low dietary carbohydrate intake will impair exercise performance when compared to a moderate or high-carbohydrate intake (Maughan and Poole 1981; Greenhaff et al. 1987; Greenhaff et al. 1988a; Greenhaff et al. 1988b; Horswill et al. 1990; Davis et al. 1997; Balsom et al. 1999).

Short term fasting is also associated with a reduction in carbohydrate availability. Nilsson and Hultman (1973) have reported that a $24 \mathrm{~h}$ fast will reduce hepatic glycogen to $10-25 \%$ of the normal level. The decreased glucose availability would certainly influence the ability to perform prolonged moderate intensity exercise as this type of exercise, if adequate fluid is ingested, has been shown to be dependent on the ability to maintain a high rate of carbohydrate supply and oxidation (Coggan and Coyle 1987;1988). However, for the performance of high-intensity exercise of short duration, 
the supply of blood glucose to the working muscles appears to be of minimal importance (Katz et al. 1986). Katz and co-workers (1986) have suggested that above $75 \%$ of $\dot{\mathrm{V}} \mathrm{O}_{2}$ max glucose uptake by the working musculature exceeds utilization. These investigators have calculated that during exercise at a workload requiring $100 \%$ of $\dot{\mathrm{V}} \mathrm{O}_{2}$ max, blood glucose provides approximately $1 \%$ of the carbohydrate utilized with muscle glycogen providing the other $99 \%$. Thus, the reduced liver glycogen stores probably did not limit muscle substrate availability to muscle during exercise in the fasted condition.

It is possible that the reduced carbohydrate intake prior to exercise in the fasted condition resulted in a reduction in cerebral glycogen and glucose prior to exercise (Dalsgaard 2006). Brain glycogenolysis supports neuronal activity and it has been suggested that the astrocyte glycogen level could reach critically low levels and result in central fatigue (Dalsgaard 2006). Indeed Nybo et al. (2003) have reported that prolonged exercise without carbohydrate supplementation led to a reduced central activation of muscle (indicative of central fatigue) when compared to the central activation when carbohydrate was fed during exercise. Thus, it appears that a 27 hour fast results in a reduction in carbohydrate availabilitydirectly and through lowered carbohydrate metabolites and that this may result in premature fatigue through CNS mechanisms. Future investigations should evaluate whether central fatigue is a plausible mechanism for the fatigue that occurs due to a 24 hour fast using electrical stimulation studies to evaluate central activation failure.

Hypohydration is another possible contributing factor to the decreased exercise capacity with a 27 hour fast. Indeed, studies examining Ramadan fasting, which is the Muslim practice of fasting during daylight hours, suggest that hypohydration occurs as a result of a disruption in normal eating and drinking habits (Leiper et al. 2003). As discussed by Leiper et al. (Leiper et al. 2003) in situations where the usual eating and drinking patterns are disrupted, there is greater reliance on physiological stimuli directly related to body water deficits. Significant hypohydration (2\%) may occur prior to the individual sensing the need to ingest fluid. However, hypohydration was likely not a significant contributor to the reduction in exercise capacity in the present investigation as Armstrong et al. (Armstrong et al. 1985) reported only a $3 \%$ impairment in $1500 \mathrm{~m}$ running performance when a body weight deficit of $1,9 \%$ was incurred through the use of diuretics. The $1500 \mathrm{~m}$ is run at an intensity that approximates $\dot{\mathrm{V}}_{2}$ max. The fasting induced decrement in body weight in the present investigation was only $1.3 \%$ for the FC condition and $0,7 \%$ for the FT condition while the overall reduction in exercise capacity was $16 \%$ for FC and $19 \%$ for FT.

Another potential contributor to reduced highintensity exercise capacity is reduced pyruvate dehydrogenase activity. Pyruvate dehydrogenase (PDH) catalyzes the conversion of pyruvate to acetyl co-A and thus irreversible conversion of glucose and glucose 6-phosphate to an essential component of the citric-acid cycle. Thus, the optimal functioning of pyruvate dehydrogenase is extremely important for the optimal use of muscle glycogen and blood glucose via aerobic metabolism. The aerobic contribution to energy metabolism during exercise that lasts $2 \mathrm{~min}$ is $\sim 65 \%$ (Medbo and Tabata 1989). A very small amount of this energy is provided by fat with almost all of it being provided by carbohydrate and almost entirely by muscle glycogen (Katz, Broberg et al. 1986). Thus, any reduction in PDH activity would reduce the ATP derived from the aerobic oxidation of glucose or glycogen.

Spriet et al. (2004), reported that the activation of pyruvate dehydrogenase was significantly lower after a $40 \mathrm{~h}$ fast (by $\sim 55-60 \%$ ) when compared to the pre-fast level. Thus, it is plausible that the 27 hour fast resulted in impaired PDH activation and that this resulted in impaired aerobic energy provision from carbohydrate and contributed to the reduced exercise capacity seen in the fasted conditions. The mechanism for the impaired PDH activity appears to be through increased activation of pyruvate dehydrogenase kinase- 4 which acts to reversibly phosphorylate PDH (Peters, Harris et al. 2001; Spriet, Tunstall et al. 2004).

Interestingly, Pichard et al. (1988) reported that fasting (for 48 hours) resulted in a reduction in the resting phosphocreatine/phosphate, the Phosphocreatine/ATP, the free energy change of ATP hydrolysis. Further, ADP levels were elevated in the fasted rats compared to the control rats. Thus, although the mechanism has not been elucidated, it appears that energy metabolism is impaired and that there is an imbalance between ATP production and utilization even in the resting non-exercise condition.

In summary, the ingestion of sodium bicarbonate did not restore the high-intensity exercise capacity impaired by a 27 hour fast. Thus, circulatory acidosis does not appear to be the cause of fatigue during high-intensity exercise as a result of 27 hour fast. The contributing factors to fatigue as a result of a one day fast remain to be elucidated but intramuscular acidosis, reduced muscle glycogen 
content in type II fibres, reduced cerebral glycogen and/or glucose availability, hypohydration, and/

\section{References}

1. Armstrong L.E., D.L. Costill et al. (1985) Influence of diuretic-induced dehydration on competitive running performance. Med Sci Sports Exerc 17(4) : 456-461.

2. Balsom, P. D., G. C. Gaitanos, et al. (1999). Highintensity exercise and muscle glycogen availability in humans. Acta Physiol Scand 165(4): 337-45.

3. Bergstrom, J., L. Hermansen, et al. (1967). Diet, muscle glycogen and physical performance. Acta Physiol Scand 71(2): 140-50.

4. Boobis, L. H. and R. J. Maughan (1983). A simple onestep enzymatic fluorometric method for the determination of glycerol in 20 microliters of plasma. Clin Chim Acta 132(2): 173-9.

5. Costill, D. L., F. Verstappen, et al. (1984). Acid-base balance during repeated bouts of exercise: influence of $\mathrm{HCO} 3$. Int J Sports Med 5(5): 228-31.

6. Coyle, E. F., A. R. Coggan, et al. (1985). Substrate usage during prolonged exercise following a preexercise meal. J Appl Physiol 59(2): 429-33.

7. Dalsgaard, M. K. (2006). Fuelling cerebral activity in exercising man. J Cereb Blood Flow Metab 26(6): 731-50.

8. Davis, J. M., D. A. Jackson, et al. (1997). Carbohydrate drinks delay fatigue during intermittent, high-intensity cycling in active men and women. Int J Sport Nutr 7(4): 261-73.

9. Essen, B., E. Jansson, et al. (1975). Metabolic characteristics of fibre types in human skeletal muscle. Acta Physio Scand 95(2): 153-65.

10. Faulkner, J., D. Claflin, et al. (1986). Power output of fast and slow fibres from human skeletal muscles. . Human Muscle Power. N. L. Jones, N. McCartney and A. McComas. Champaign, IL, Human Kinetics: 81-91.

11. Forster, H. V., J. A. Dempsey, et al. (1972). Estimation of arterial PO2, PCO2, $\mathrm{pH}$, and lactate from arterialized venous blood. J Appl Physiol 32(1): 134-7.

12. Gleeson, M., P. L. Greenhaff, et al. (1988). Influence of a $24 \mathrm{~h}$ fast on high intensity cycle exercise performance in man. Eur J Appl Physiol Occup Physiol 57(6): 653-9.

13. Greenhaff, P. L., M. Gleeson, et al. (1988). The effects of a glycogen loading regimen on acid-base status and blood lactate concentration before and after a fixed period of high intensity exercise in man. Eur J Appl Physiol Occup Physiol 57(2): 254-9.

14. Greenhaff, P. L., M. Gleeson, et al. (1988). The effects of diet on muscle $\mathrm{pH}$ and metabolism during high intensity exercise. Eur J Appl Physiol Occup Physiol 57(5): 531-9.

15. Greenhaff, P. L., M. Gleeson, et al. (1987). Dietary composition and acid-base status: limiting factors in the performance of maximal exercise in man? Eur J Appl Physiol Occup Physiol 56(4): 444-50.

16. Greenhaff, P. L., J. M. Ren, et al. (1991). Energy metabolism in single human muscle fibers during contraction without and with epinephrine infusion. Am J Physiol 260(5 Pt 1): E713-8.

17. Harris, R. C., B. Essen, et al. (1976). Glycogen phosphorylase activity in biopsy samples and single muscle fibres of musculus quadriceps femoris of man at rest. Scand J Clin Lab Invest 36(6): 521-6.

18. Hermansen, L. (1981). Effect of metabolic changes on force generation in skeletal muscle during maximal exercise. Ciba Found Symp 82: 75-88.

19. Hirche, H. J., V. Hombach, et al. (1975). Lactic acid permeation rate in working gastrocnemii of dogs during metabolic alkalosis and acidosis. Pflugers Arch 356(3): 209-22. or reduced $\mathrm{PDH}$ activity are plausible but unproven explanations for the reduction in exercise capacity.

20. Horswill, C. A., R. C. Hickner, et al. (1990). Weight loss, dietary carbohydrate modifications, and high intensity, physical performance. Med Sci Sports Exerc 22(4): 470-6.

21. Hultman, E. (1967). Studies on muscle metabolism of glycogen and active phosphate in man with special reference to exercise and diet. Scand J Clin Lab Invest Suppl 94: 1-63.

22. Jones, N. L., J. R. Sutton, et al. (1977). Effect of pH on cardiorespiratory and metabolic responses to exercise. J Appl Physiol 43(6): 959-64.

23. Katz, A., S. Broberg, et al. (1986). Leg glucose uptake during maximal dynamic exercise in humans. Am J Physiol 251(1 Pt 1): E65-70.

24. Leiper JB., et al. (2003) Effects on health of fluid restriction during fasting in Ramadan. Eur J Clin Nutr 57(2):530-538.

25. Loy, S. F., R. K. Conlee, et al. (1986). Effects of 24hour fast on cycling endurance time at two different intensities. J Appl Physiol 61(2): 654-9.

26. Maughan, R. J. (1982). A simple, rapid method for the determination of glucose, lactate, pyruvate, alanine, 3-hydroxybutyrate and acetoacetate on a single 20-mul blood sample. Clin Chim Acta 122(2): 231-40.

27. Maughan, R. J. and M. Gleeson (1988). Influence of a $36 \mathrm{~h}$ fast followed by refeeding with glucose, glycerol or placebo on metabolism and performance during prolonged exercise in man. Eur J Appl Physiol Occup Physiol 57(5): 570-6.

28. Maughan, R. J. and D. C. Poole (1981). The effects of a glycogen-loading regimen on the capacity to perform anaerobic exercise. Eur J Appl Physiol Occup Physiol 46(3): 211-9.

29. Maughan, R. J. and C. Williams (1981). Differential effects of fasting on skeletal muscle glycogen content in man and on skeletal and cardiac muscle glycogen content in the rat. Proc Nutr Soc 40: 85A.

30. Medbo, J. I. and I. Tabata (1989). Relative importance of aerobic and anaerobic energy release during short-lasting exhausting bicycle exercise. J Appl Physiol 67(5): 1881-6.

31. Nieman, D. C., K. A. Carlson, et al. (1987). Running endurance in 27-h-fasted humans. J Appl Physiol 63(6): 2502-9.

32. Nilsson, L. H. and E. Hultman (1973). Liver glycogen in man--the effect of total starvation or a carbohydrate-poor diet followed by carbohydrate refeeding. Scand J Clin Lab Invest 32(4): 325-30.

33. Nybo, L. (2003). CNS fatigue and prolonged exercise: effect of glucose supplementation. Med Sci Sports Exerc 35(4): 589-94.

34. Pequignot, J. M., L. Peyrin, et al. (1980). Catecholamine-fuel interrelationships during exercise in fasting men. J Appl Physiol 48(1): 109-13.

35. Peters, S. J., R. A. Harris, et al. (2001). Muscle fiber type comparison of PDH kinase activity and isoform expression in fed and fasted rats. Am J Physiol Regul Integr Comp Physiol 280(3): R661-8.

36. Pichard, C., C. Vaughan, et al. (1988). "Effect of dietary manipulations (fasting, hypocaloric feeding, and subsequent refeeding) on rat muscle energetics as assessed by nuclear magnetic resonance spectroscopy. J Clin Invest 82(3): 895-901.

37. Spriet, L. L., R. J. Tunstall, et al. (2004). "Pyruvate dehydrogenase activation and kinase expression in human skeletal muscle during fasting. J Appl Physiol 96(6): 2082-7.

38. Sutton, J. R., N. L. Jones, et al. (1981). Effect of PH on muscle glycolysis during exercise. Clin Sci (Lond) 61(3): 331-8.

Надійшла 22.12.2013 